\title{
Post-intensive care syndrome: An overview
}

\author{
Gautam Rawal $^{1}$, Sankalp Yadav ${ }^{2}$, Raj Kumar ${ }^{3}$ \\ ${ }^{1}$ Attending Consultant, Respiratory Intensive Care, Max Super Specialty Hospital, \\ Saket, New Delhi, India; \\ ${ }^{2}$ General Duty Medical Officer-II, Department of Medicine \& TB, Chest Clinic Moti Nagar, \\ North Delhi Municipal Corporation, New Delhi, India; \\ ${ }^{3}$ Senior Consultant and Incharge, Respiratory Intensive Care, Max Super Specialty Hospital, \\ Saket, New Delhi, India
}

\section{ABSTRACT}

Survival of critically unwell patients has improved in the last decade due to advances in critical care medicine. Some of these survivors develop cognitive, psychiatric and /or physical disability after treatment in intensive care unit (ICU), which is now recognized as post intensive care syndrome (PICS). Given the limited awareness about PICS in the medical faculty this aspect is often overlooked which may lead to reduced quality of life and cause a lot of suffering of these patients and their families. Efforts should be directed towards preventing PICS by minimizing sedation and early mobilization during ICU.All critical care survivors should be evaluated for PICS and those having signs and symptoms of it should be managed by a multidisciplinary team which includes critical care physician, neuro-psychiatrist, physiotherapist and respiratory therapist,with the use of pharmacological and non-apharmacological interventions. This can be achieved through an organizational change and improvement, knowing the high rate of incidence of PICS and its adverse effects on the survivor's life and daily activities and its effect on the survivor's family.

Key words: cognition, critical illness, intensive care, syndrome

\section{INTRODUCTION}

The advancement in the critical care medicine and consequently, the improvement in survival after a critical illness have led the clinicians to discover the significant functional disabilities that many of these surviving patients suffer. This has led to further research which is focused on improving the long-term outcomes for the critical illness survivors and their functional recovery.

Post-intensive care syndrome (PICS) describes the disability that remains in the surviving the critical illness. This comprises of impairment in cognition, psychological health, and physical function of the intensive care unit (ICU) survivor. ${ }^{[1,2]}$ Consequent to this, the psychological health of family members of the survivor may also be affected in an adverse manner, termed as PICS-Family (PICS-F). ${ }^{[1,2]}$
PICS is defined as new or worsening impairment in physical (ICU-acquired neuromuscular weakness), cognitive (thinking and judgment), or mental health status arising after critical illness and persisting beyond discharge from the acute care setting. ${ }^{[1,2]}$

PICS-F refers to the acute and the chronic psychological effects of critical illness on the family of the patient and includes the symptoms that are experienced by family members during the critical illness as well as those that occur following death or discharge of a loved one from the ICU. ${ }^{[1-4]} \mathrm{It}$ has been observed that up to $30 \%$ of family or the caregivers experience stress, anxiety, depression, and complicated grief. ${ }^{[3,4]}$

\section{INCIDENCE AND RISK FACTORS OF DIFFERENT COMPONENTS OF PICS}

PICS is now being recognized as a public health burden due to the associated 
neuropsychological and functional disability, however its exact prevalence remains unknown.

Cognitive impairment: It has been reported to occur on average in $25 \%$ of ICU survivors, but few studies have shown its incidence to be significantly high, occurring in more than $3 / 4$ th of ICU survivors. ${ }^{[5-7]}$ The major risk factors associated with it are duration of delirium in ICU, acute brain dysfunction (stroke, alcoholism), hypoxia (ARDS, cardiac arrest), hypotension (severe sepsis, trauma), glucose dysregulation, respiratory failure requiring prolonged mechanical ventilation, severe sepsis, use of renal replacement therapy, and acute respiratory distress syndrome (ARDS), prior cognitive impairment (older age, preexisting cognitive deficits, premorbid health conditions) $\cdot^{[8-12]}$

Psychiatric illnesses: The risk of developing psychological disability after discharge from intensive care, ranges from one to sixty two percent $(\%)$ in the form of depression, anxiety, and post-traumatic stress disorder (PTSD) ${ }^{[6,12-15]}$ The risk factors are same as for cognitive impairment and also include the female gender, lower education level, preexisting disability, and the use of sedation and analgesia in ICU. ${ }^{[14-16]}$

Physical: ICU-acquired neuromuscular weakness is the most common form of physical impairment occurring more than $25 \%$ of ICU survivors (poor mobility, recurrent falls, or quadri or tetra paresis) ${ }^{[17-19]}$ Conditions strongly associated with the development of ICU-acquired weakness include prolonged mechanical ventilation ( $>7$ days), sepsis, multisystem organ failure, as well as prolonged duration of the bed-restore deep sedation. ${ }^{[20-22]}$

\section{CLINICAL MANIFESTATIONS}

The presentation of PICS can be varied (combination of cognitive, psychological, and physical signs and symptoms), the main feature being that these are newly recognized or get worsened after recovering from a critical illness. The symptoms can last for a few months to many years post recovery. ${ }^{[22-23]}$ The common symptoms include generalized weakness, fatigue, decreased mobility, anxious or depressed mood, sexual dysfunction, sleep disturbances, and cognitive issues (memory disturbance/loss, slow mental processing, poor concentration and so on).

Family members of the critically ill patients can be affected similarly (physically and psychologically) during the ICU stay of their loved one and the effects may persist after discharge. The major risk factors for PICS-F are poor communication between staff, being in a decision-making role, lower educational level, and having a loved one who died or was close to death. The most common problems experienced by family members include sleep deprivation, anxiety, depression, complicated grief, and PTSD. ${ }^{[23]}$

\section{PREVENTION AND MANAGEMENT (THE ABCDE BUNDLE)}

All patients being admitted into the ICU facility should undergo a psychological evaluation that includes: (a) preadmission history, (b) ability to adapt to stress in past, (c) medication history, (d) current mental and clinical status, and (e) environmental and family factors. The treatment of the ICU syndrome includes: (a) the elimination or correction of causative factors, (b) the appropriate administration of sedatives (anxiolytic and antipsychotic agents), (c) reduction or elimination of sources of environmental stress, and (d) frequent patient and family communication.

As always said "Prevention is better than cure," the same implies for the management of PICS. The most important preventive strategies shown to have a positive impact in preventing the long-term functional disabilities associated with PICS include limiting the use of deep sedation and encouraging early mobility in the ICU patients, along with aggressive physical and occupational therapy. ${ }^{[2-27]}$ This requires a multidisciplinary approach for the best outcome and successful management.

The ABCDE bundle has been used with good preventive rates for PICS. ${ }^{[25,27-29]}$ This comprises of:

Awakening (using light or minimal sedation);

Breathing (spontaneous breathing trials);

Coordination of care and communication among various disciplines;

Delirium monitoring, assessment, and management;

Early ambulation in the ICU.

Additional interventions to prevent PICS include: (1) Avoiding hypoglycemia and hypoxemia. (2) ICU diaries: Maintenance of ICU diary prospectively by the family members, health care providers, or both during the patient's ICU stay, has shown to decrease symptoms of PTSD, and can be used as a holistic tool to provide support and care to the patient and family. ${ }^{[29-30]}$ (3) Creating post-ICU clinics to provide follow-up counseling and support to the patients and family. ${ }^{[31]}$ Clinicians should also provide proper education about resources that assist in promoting rehabilitation. (4) Maintaining good nutritional status and adequate sleep of the patient.

Depression, anxiety, and PTSD are treated with a combination of pharmacotherapy and non-pharmacological, psychological, and behavioral therapies. ${ }^{[15]}$ 
Physical dysfunction requires a multidisciplinary treatment program that includes exercise, physiotherapy, occupational therapy, and symptom management including rehabilitation.

\section{CONCLUSIONS}

The above article emphasizes on the physician's awareness of PICS in the patients surviving a critical illness and the irresponsibility towards the patients beyond saving their lives. The extra effort, time and care by forming a multidisciplinary management plan can improve the long-term functioning capacity and quality of life of the ICU survivors and also their families.

\section{Conflicts of Interest}

\author{
None declared
}

\section{REFERENCES}

1. Needham DM, Davidson J, Cohen H, Hopkins RO, Weinert C, Wunsch H, et al. Improving long-term outcomes after discharge from intensive care unit: Report from a stakeholders' conference. Crit Care Med 2012;40:502-9.

2. Medicine SoCC. Post-Intensive Care Syndrome Patients and Families 2013; Available from URL: http://www.myicucare.org/Adult-Support/Pages/ Post-intensive-Care-Syndrome.aspx. Last accessed 2016 January 10.

3. Davidson JE, Jones C, Bienvenu OJ. Family response to critical illness: postintensive care syndrome-family. Critical Care Med 2012;40:618-24.

4. Schmidt M, Azoulay E. Having a loved one in the ICU: the forgotten family. Curr Opin Crit Care 2012;18:540-7.

5. Needham DM, Dinglas VD, Morris PE, Jackson JC, Hough CL, MendezTellez PA, et al. Physical and cognitive performance of patients with acute lung injury 1 year after initial trophic versus full enteral feeding. EDEN trial follow-up. Am J Respir Crit Care Med 2013; 188:567-76.

6. Pandharipande PP, Girard TD, Jackson JC, Morandi A, Thompson JL, Pun $\mathrm{BT}$, et al. Long-term cognitive impairment after critical illness. N Engl J Med 2013;369:1306-16.

7. Davydow DS, Zatzick D, Hough CL, Katon WJ. In-hospital acute stress symptoms are associated with impairment in cognition 1 year after intensive care unit admission. Ann Am Thorac Soc 2013;10:450-57.

8. Iwashyna TJ, Ely EW, Smith DM, Langa KM. Long-term cognitive impairment and functional disability among survivors of severe sepsis. JAMA 2010;304:1787-94.

9. Mikkelsen ME, Christie JD, Lanken PN, Biester RC, Thompson BT, Bellamy SL, et al. The adult respiratory distress syndrome cognitive outcomes study: long-term neuropsychological function in survivors of acute lung injury. Am J Respir Crit Care Med 2012;185:1307-15.

10. Yaffe K, Weston A, Graff-Radford NR, Satterfield S, Simonsick EM, YounkinSG, et al. Association of plasma beta-amyloid level and cognitive reserve with subsequent cognitive decline. JAMA 2011;305:261-6.

11. Davydow DS, Hough CL, Langa KM, Iwashyna TJ. Pre sepsis depressive symptoms are associated with incident cognitive impairment in survivors of severe sepsis: a prospective cohort study of older Americans. J Am Geriatr Soc 2012;60:2290-6.

12. Hopkins RO, Weaver LK, Collingridge D, Parkinson RB, Chan KJ, Orme JF Jr. Two-year cognitive, emotional, and quality-of-life outcomes in acute respiratory distress syndrome. Am J Respir Crit Care Med 2005; 171:340-7.
13. Desai SV, Law TJ, Needham DM. Long-term complications of critical care. Crit Care Med 2011;39:371-9.

14. Wunsch H, Christiansen CF, Johansen MB, Olsen M, Ali N, Angus DC, et al. Psychiatric diagnoses and psychoactive medication use among nonsurgical critically ill patients receiving mechanical ventilation. JAMA 2014;311:1133-42.

15. Rawal G, Yadav S, Kumar R. Post-Traumatic Stress Disorder: A Review from Clinical Perspective. Int J Indian Psychol 2016; 3:156-64.

16. Jackson JC, Pandharipande PP, Girard TD, Brummel NE, Thompson JL, Hughes CG, et al. Depression, post-traumatic stress disorder, and functional disability in the BRAIN-ICU study: a longitudinal cohort study. Lancet Respir 2014;2:369-79.

17. Fan E, Dowdy DW, Colantuoni E, Mendez-Tellez PA, Sevransky JE, Shanholtz C, et al. Physical complications in acute lung injury survivors: a two-year longitudinal prospective study. Crit Care Med 2014;42:849-59.

18. Hermans G, Van Mechelen H, Clerckx B, Vanhullebusch T, Mesotten D, Wilmer A, et al. Acute outcomes and 1-year mortality of intensive care unit-acquired weakness: A cohort study and propensity-matched analysis. Am J Respir Crit Care Med 2014;190:410-20.

19. Fan E, Cheek F, Chlan L, Gosselink R, Hart N, Herridge MS, et al. An official American Thoracic Society Clinical Practice guideline: the diagnosis of intensive care unit-acquired weakness in adults. Am J Respir Crit Care Med 2014;190:1437-46.

20. Needham DM, Wozniak AW, Hough CL, Morris PE, Dinglas VD, Jackson JC, et al. Risk Factors for Physical Impairment after Acute Lung Injury in a National, Multicenter Study. Am J Respir Crit Care Med 2014;189:1214-24.

21. Schweickert WD, Hall J. ICU-acquired weakness. Chest 2007;131:1541-9.

22. Fletcher SN, Kennedy DD, Ghosh IR, Misra VP, Kiff K, Coakley JH, et al. Persistent neuromuscular and neurophysiologic abnormalities in longterm survivors of prolonged critical illness. Crit Care Med 2003;31:1012-6.

23. Gries CJ, Engelberg RA, Kross EK, Zatzick D, Nielsen EL, Downey L, et al. Predictors of symptoms of posttraumatic stress and depression in family members after patient death in the ICU. Chest 2010;137:280-7.

24. Balas MC, Vasilevskis EE, Olsen KM, Schmid KK, Shostrom V, Cohen MZ, et al. Effectiveness and Safety of the Awakening and Breathing Coordination, Delirium Monitoring/Management, and Early Exercise/Mobility (ABCDE) Bundle. Crit Care Med 2014;42:1024-36.

25. Kress JP. Sedation and mobility: changing the paradigm. Crit Care Clin 2013;29:67-75.

26. Schweickert WD, Pohlman MC, Pohlman AS, Nigos C, Pawlik AJ, Esbrook CL, et al. Early physical and occupational therapy in mechanically ventilated, critically ill patients: a randomised controlled trial. Lancet 2009;373:1874-82.

27. Morandi A, Brummel NE, Ely EW. Sedation, delirium and mechanical ventilation: the 'ABCDE' approach. Curr Opin Crit Care 2011;17:43-9.

28. Pandharipande P, Banerjee A, McGrane S, Ely EW. Liberation and animation for ventilated ICU patients: the ABCDE bundle for the back-end of critical care. Crit Care 2010;14:157.

29. Garrouste-Orgeas M, Périer A, Mouricou P, Grégoire C, Bruel C, Brochon $S$, et al. Writing In and Reading ICU Diaries: Qualitative Study of Families' Experience in the ICU. Harris F, ed. PLoS ONE 2014;9:e110146.

30. Jones C, Bäckman C, Capuzzo M, Egerod I, Flaatten H, Granja C, et al. Intensive care diaries reduce new onset posttraumatic stress disorder following critical illness: a randomised, controlled trial. Crit Care 2010;14:R168.

31. Mehlhorn J, Freytag A, Schmidt K, Brunkhorst FM, Graf J, Troitzsch U, et al. Rehabilitation interventions for post-intensive care syndrome: a systematic review. Crit Care Med 2014;42:1263-71.

How to cite this article: Rawal G, Yadav S, Kumar R. Post-intensive care syndrome: An overview. J Transl Intern Med 2017; 5: 90-92. 